Sir,

\section{Blepharoptosis as a sign of severe Graves' orbitopathy}

Common features of active thyroid orbitopathy include eyelid and conjunctival oedema and redness, eyelid retraction, proptosis, and strabismus. Optic neuropathy may occur in $5 \%$ of cases. ${ }^{1}$ We report on a patient who developed optic neuropathy together with

blepharoptosis. Both features resolved following orbital decompression in the active stage.

\section{Case report}

A 59-year-old man was referred with a history of sudden onset of blepharoptosis of the right upper eyelid, mild retraction of the left upper eyelid, and bilateral ocular redness with eyelid oedema since 8 months (Figure 1a and $\mathrm{b}$ ). The levator function of the right eye was $3 \mathrm{~mm}$ and there was complete blepharoptosis. Elevation was bilaterally restricted, with duction values of 25 degrees. Fundoscopy showed tortuosity of the veins and papillary oedema in the right eye. The visual acuity was 6/9 OD and $6 / 6$ OS, respectively. Exophthalmometry readings were $19 \mathrm{~mm}$ bilaterally.

Laboratory investigations revealed autoimmune hyperthyroidism. Orbital CT scan examination showed bilateral thickening of rectus muscles (Figure 2a). We ruled out myasthenia gravis and intracranial lesions. Despite treatment with oral and intravenous steroids his

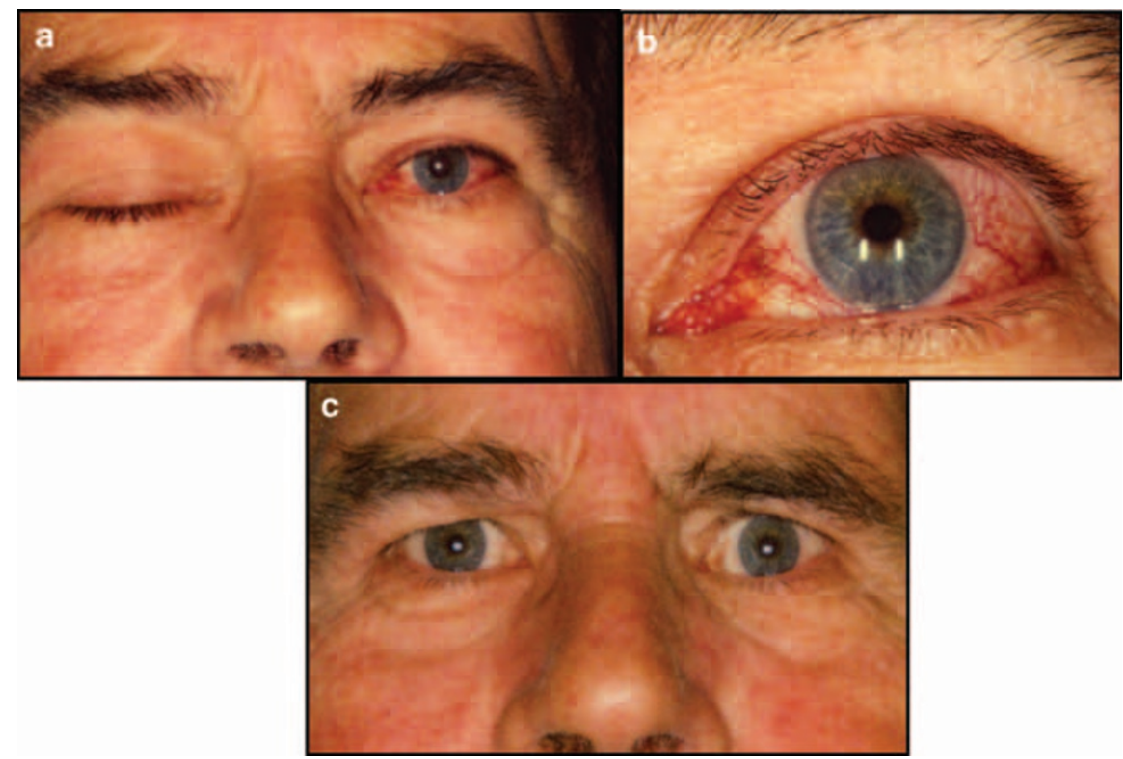

Figure 1 (a) Right eye blepharoptosis before orbital decompression. Preoperative levator function was 3 and $14 \mathrm{~mm}$ of the right and left upper eyelids, respectively. (b) Left eye upper eyelid retraction and congestive Graves' orbitopathy before orbital decompression. (c) Resolution of the right eye blepharoptosis after orbital decompression. Note the bilateral upper eyelid retraction, masked by upper lid dermatochalasis. Postoperative levator function was 13 and $14 \mathrm{~mm}$ of the right and left upper eyelid, respectively.
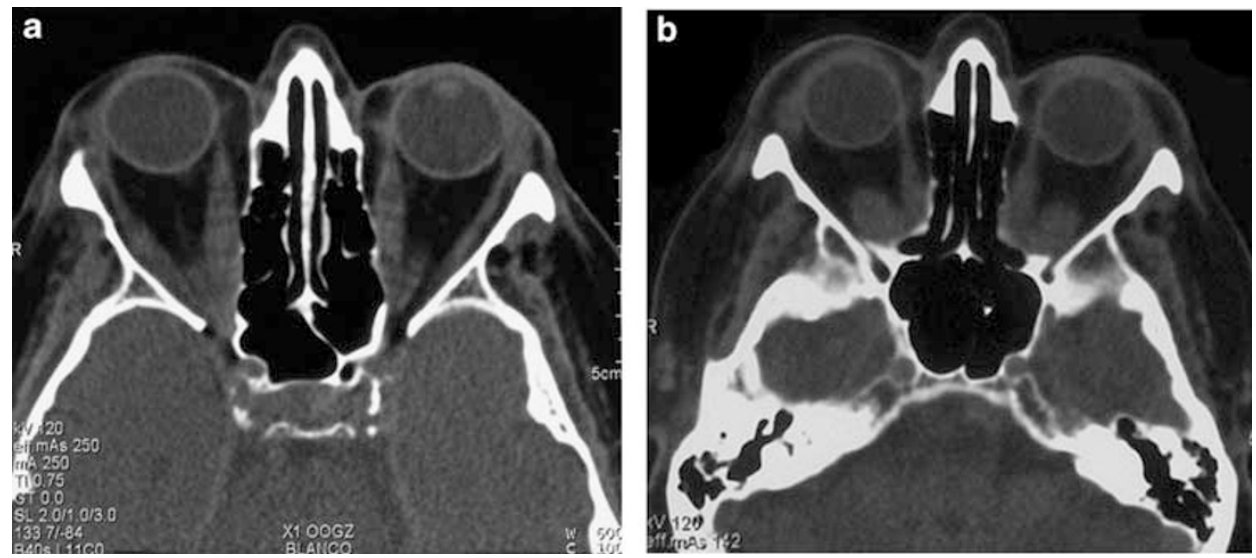

Figure 2 (a) Bilateral proptosis with enlarged extraocular muscles prior to orbital decompression. Apical compression of the optic nerve (axial CT scan). Preoperative exophthalmometry values were 19-19-93. (b) Bilateral herniation of the orbital tissues into the ethmoid sinus after transconjunctival inferomedial orbital decompression (axial CT scan). Postoperative exophthalmometry values were 16-16-90. 
orbitopathy progressed. Consequently, he underwent bilateral transconjunctival inferomedial orbital decompression. Postoperatively, the blepharoptosis and signs of bilateral optic nerve compression resolved over a period of 5 months (Figure 2b). Subsequently, bilateral upper eyelid retraction was noted (Figure 1c).

\section{Comment}

We hypothesize that the blepharoptosis was caused by a first degree injury due to compression and ischaemia of the branch of the oculomotor nerve supplying the Levator in the orbit. In first-degree oculomotor nerve injuries, which frequently result from microvascular obstruction, the continuity of the axons is maintained. ${ }^{2}$ Hence, full function returns once the flow is restored. The aetiology of the oculomotor nerve compression could be similar to that of optic nerve compression induced by apical crowding in a particularly tight orbit. ${ }^{3,4}$ Hence, blepharoptosis in a patient with thyroid orbitopathy may indicate apical compression.

\section{References}

1 Chang EL, Bernardino CR, Rubin PA. Transcaruncular orbital decompression for management of compressive optic neuropathy in thyroid-related orbitopathy. Plast Reconstr Surg 2003; 112(3): 739-747.

2 Weber ED, Newman SA. Aberrant regeneration of the oculomotor nerve: implications for neurosurgeons. Neurosurg Focus 2007; 23(5): E14.

3 Boulos PR, Hardy I. Thyroid-associated orbitopathy: a clinicopathologic and therapeutic review. Curr Opin Ophthalmol 2004; 15(5): 389-400.

4 Giaconi JA, Kazim M, Rho T, Pfaff C. CT scan evidence of dysthyroid optic neuropathy. Ophthal Plast Reconstr Surg 2002; 18(3): 177-182

\section{Naseem, DLT Donker and D Paridaens}

Oculoplastic and Orbital Service, Rotterdam Eye

Hospital, Rotterdam, The Netherlands

Correspondence: D Paridaens,

Oculoplastic and Orbital Service,

Rotterdam Eye Hospital,

P.O. Box 70030, 3000 LM Rotterdam,

The Netherlands

Tel + 31(0) 104017777 ;

Fax + 31(0) 104111747.

E-mail: paridaens@icapi.nl

Eye (2009) 23, 1743-1744; doi:10.1038/eye.2008.333; published online 31 October 2008

\section{Sir,}

Inadvertent injection of intravitreal air during intravitreal Lucentis injection for wet age-related macular degeneration: an undescribed complication

The frequency of intravitreal injections is increasing after landmark age-related macular degeneration studies, ${ }^{1,2}$ and to a lesser extent evidence for the efficacy of intravitreal triamcinolone for diabetic maculopathy. ${ }^{3}$ Several uncommon complications are described, namely infectious and non-infectious endophthalmitis, iatrogenic lesions to the intraocular structures leading to retinal detachment or cataract and steroid-induced glaucoma. ${ }^{4}$

Two patients receiving intravitreal ranibizumab (Lucentis) for wet age-related macular degeneration complained immediately after their injection of unusual visual symptoms, 'like looking through an hour glass,' particularly when looking down. Ocular examination revealed multiple small intravitreal air bubbles with no entry site breaks or vitreous floaters.

This is an important observation for several reasons. Most importantly, these bubbles produced disturbing symptoms in the patients that they were not expecting. Air within the syringe could also alter the administered dose of the drug. Finally, it is well documented that intravitreal gas presents a risk during air flight. ${ }^{5}$ The volume involved here is low, but we should be aware that this is a potential complication of intravitreal injections and should take appropriate measures to avoid these symptoms and potential complications by actively checking the syringe and needle before injection to ensure that no air has been drawn up when preparing the drug for injection.

\section{References}

1 Rosenfeld PJ, Brown DM, Heier JS, Boyer DS, Kaiser PK, Chung CY et al., MARINA Study Group. Ranibizumab for neovascular age-related macular degeneration. $N$ Engl J Med 2006; 355(14): 1419-1431.

2 Brown DM, Kaiser PK, Michels M, Soubrane G, Heier JS, Kim RY et al., ANCHOR Study Group. Ranibizumab versus verteporfin for neovascular age-related macular degeneration. N Engl J Med 2006; 355(14): 1432-1444.

3 Grover D, Li TJ, Chong CC. Intravitreal steroids for macular edema in diabetes. Cochrane Database Syst Rev 2008; (1): CD005656.

4 Jonas JB, Spandau UH, Schlichtenbrede F. Short-term complications of intravitreal injections of triamcinolone and bevacizumab. Eye 2008; 22(4): 590-591.

5 Mills MD, Devenyi RG, Lam WC, Berger AR, Beijer CD, Lam SR. An assessment of intraocular pressure rise in patients with gas-filled eyes during simulated air flight. Ophthalmology 2001; 108(1): 40-44.

\section{JEA Somner ${ }^{1}$ and D Mansfield ${ }^{2}$}

${ }^{1}$ Department of Ophthalmology, The Tennent Institute of Ophthalmology, Gartnavel General Hospital, Glasgow, UK

${ }^{2}$ Department of Ophthalmology, Inverclyde Royal

Hospital, Inverclyde, UK

E-mail: jsomner@googlemail.com

\section{Conflict of Interest: None}

Eye (2009) 23, 1744; doi:10.1038/eye.2008.297; published online 3 October 2008 